\title{
Margaret McCartney: Clean eating and the cult of healthism
}

\author{
Margaret McCartney GP
}

Glasgow

The new way of eating is "eating clean"-healthy, whole, unprocessed foods. If only that were all: note the stacks of açaí berries, coconut oil, cashew butter, and the expanding wheat-free shelf in the more expensive supermarkets. More choice is a good thing for people with coeliac disease-but these products aren't aimed at them.

Bestselling cookbooks tell the public that they'll look and feel better by avoiding wheat, dairy, and refined sugar. City centre juice bars offer similar promises to increase wellbeing (a favourite phrase).

Last month I went to a new gym class. At the end the instructor dismissed the sweaty masses with high fives and directions to drink juice and rehydrate fulsomely. "If you feel thirsty you're already dehydrated," was the fear-mongering message, and I would've protested had I been less breathless. Many attendees took possession of pre-ordered portions of coconut water and miserable looking vegetable purées. Follow-up emails from the gym have included much anti-science: not just a clean but also an alkaline diet, numerous supplements, and standing upside down to detoxify.

Food should be our pleasurable fuel, not our quest and destination. We're all going to die, regardless of how much quinoa we eat

The command to eat cleanly implies that everyone else is filthy, being careless with their bodies and lives. It comes with promises of energy boosts, glowing skin, spirituality, purity, and possibly immortality. But this nonsense is all based on a loose interpretation of facts and a desire to make the pursuit of wellbeing an obsessive, full time occupation.

Some of the behaviours being encouraged by the gym and "clean" cookbooks are worrying. The minuscule meals, routine self denial, intensive exercise, and calorie counting seem to be an obsessive quest for a beautiful body and spiritual nirvana. "Cheat meals"- a deviation from clean eating — are frowned on, with terrible threats of constipation and feeling sluggish or bloated. The word "orthorexia," an obsession with eating only healthily, is used to describe this phenomenon, and some of this behaviour is surely on the eating disorder spectrum.

"Nutritionist" is an unregistered title, so anyone can claim to be one. They are legion and loved by the media, claiming new superfoods and diets in the way Columbus found new horizons. "Dietitians" have a protected title, ${ }^{1}$ as they are taught evidence based facts and like to talk about the uncertainties in diet studies. They also tend not to get such media coverage.

Food should be our pleasurable fuel, not our quest and destination. We're all going to die, regardless of how much quinoa we eat. If we've "had enough of experts," as one UK politician recently claimed, this sort of thing can only proliferate. We need clean facts, and dietitians need to be much more visible in our post-facts world.

British Dietetic Association. Dietician, nutritionist, nutritional therapist, or diet expert? 2014. https://www.bda.uk.com/publications/dietitian_nutritionist.pdf.

Published by the BMJ Publishing Group Limited. For permission to use (where not already granted under a licence) please go to http://group.bmj.com/group/rights-licensing/ permissions 